\title{
Liquid-Liquid Extraction/Low-Temperature Purification (LLE/LTP) Followed by Dispersive Solid-Phase Extraction (d-SPE) Cleanup for Multiresidue Analysis in Palm Oil by LC-QTOF-MS
}

\author{
Elham Sobhanzadeh and Keivan Nemati \\ Department of Chemistry, Islamic Azad University, Masjed-Soliman Branch, Masjed-Soliman, Iran \\ Correspondence should be addressed to Elham Sobhanzadeh; elham.sobhanzadeh@yahoo.com
}

Received 4 June 2012; Revised 28 August 2012; Accepted 28 August 2012

Academic Editor: Javier Hernandez-Borges

Copyright (C) 2013 E. Sobhanzadeh and K. Nemati. This is an open access article distributed under the Creative Commons Attribution License, which permits unrestricted use, distribution, and reproduction in any medium, provided the original work is properly cited.

\begin{abstract}
An evaluation of the extraction of multiresidue pesticides from palm oil by liquid-liquid extraction/low-temperature purification (LLE/LTP) coupled with dispersive solid-phase extraction (d-SPE) as the cleanup procedure with the determination by liquid chromatography mass spectrometry using electrospray as the ionization source (LC-ESI-MS) was carried out. Optimization approaches were studied in terms of d-SPE to select efficiency of type and mass of adsorbents to obtain the highest recovery yield of pesticides and the lowest coextract fat residues in the final extract. The optimal conditions of d-SPE were obtained using $3 \mathrm{~g}$ of palm oil, $4 \mathrm{~g}$ anhydrous $\mathrm{MgSO}_{4}, 150 \mathrm{mg}$ of PSA, and $50 \mathrm{mg}$ of GCB (PSA: GCB (3:1 w/w)). Recovery study was performed at three concentration levels $\left(25,50\right.$, and $\left.100 \mathrm{ng} \mathrm{kg}^{-1}\right)$, yielding recovery rates between 71.8 and $112.4 \%$ except diuron with relative standard deviations of 3.2-15.1\%. Detection and quantification limits were lower than 2.7 and $8.2 \mathrm{ng} \mathrm{kg}^{-1}$, respectively. The proposed method was successfully applied to the analysis of market-purchased palm oil samples from two different brands collected in Kuala Lumpur, showing its potential applicability and revealing the presence of some of the target species in the $\mathrm{ng} \mathrm{g}^{-1}$ range.
\end{abstract}

\section{Introduction}

Palm oil (Elaeis guineensis) is a very common cooking ingredient in Southeast Asia and the tropical belt of Africa. Malaysia is not only one of the leading countries in exporting palm fruit, but also is the largest exporter of palm oil in the world. According to the World Bank and the Asian Development Bank, Malaysia is the world's second largest palm oil producer [1]. Recent research in Malaysia indicates that the palm oil obtained from the flesh of the palm fruit (mesocarp) is widely used in various food products, such as margarines, shortenings, cooking oils, confectionery fats, and vanaspati without or with only minimal modification of palm oil composition, as well as in nonfood products such as oleochemicals, soaps, and biodiesel. Consumers have always wanted products with high quality and safety. In this manner, information and studies regarding pesticide residue has become a usual practice [2]. Consequently, determination of pesticide residues is at the forefront among preventive measures in public health safety. The Codex Alimentarius Committee on Pesticide residues and the Joint FAO/WHO Meeting on Pesticide Residues (JMPR) have established maximum pesticide residue limits for some of the pesticides in palms destined for oil production $[3,4]$. However, it should be noted that there are no harmonized MRLs established for pesticide residues in palm oil yet. But the National Committee on Agricultural Commodity and Food Standards issued a Notification entitled the Thai Agricultural Standards on Pesticide Residues: Maximum Residue Limits (TAS 90022006) for palm oil on 31 July 2006 which was published in the Royal Gazette [5].

Analysis of pesticide residues in complex matrices consists of four steps: extraction, extract cleaning, identification and quantification of compounds. The use of liquid chromatography coupled to mass spectrometry (LCMS) has become a valuable technique for analyzing many residues and contaminants in complex matrices such as food and environmental samples as described extensively 
in the literature [6-11]. Recent reviews on pesticides in food matrices and water have commented on the unique ability of accurate mass to identify both target compounds and nontargets by liquid chromatography time-of-flight mass spectrometry (LC-TOF-MS) [12-14]. Despite employing of powerful instrumental techniques the risk of interference increases with the complexity of the matrix studied therefore, sample preparation prior to instrumental analysis is necessary. Among the extraction methods commonly used in fatty matrices such as oil analysis, the most commonly used methodology is based on liquid-liquid partitioning extraction with solvents of different polarity [15], gel permeation chromatography (GPC) [16], microwave-assisted extraction (MAE) [17], solid-phase extraction (SPE) [18] matrix solidphase dispersion (MSPD) [19] solid-phase microextraction (SPME) [20], and supercritical fluid extraction (SFE) [21, 22]. Up to now, a limited number of analytical methods for the detection of pesticides in palm oil samples have been published. Liquid-liquid partitioning with acetonitrile followed by low-temperature cleanup in order to precipitation of lipid has been reported for determination of the herbicides fluroxypyr, also chlorpyrifos and organochlorine pesticides in crude palm oil (CPO) and crude palm kernel oil $(\mathrm{CPKO})[23,24]$. In this study, seven analytes such as dimethoate, carbaryl, simazine, atrazine, terbuhylazine, diuron, and malathion were selected among different classes of compounds (organophosphates, carbamates, triazines, and phenylureas) and based two chemical uses which are insecticides and herbicides. This work aimed to optimize and validate the efficient, sensitive and interference-free method in combination with liquid chromatography electrospray time-of-flight mass spectrometry for the determination of pesticides in palm oil. For this purpose, liquid-liquid extraction with low-temperature purification was selected as the more suitable method for the routine analysis of pesticide residues in palm oil with the advantages of low cost, nonspecific instrumentation demands and ease of carrying out. After centrifugation and freezing the fat filtration, most of the remaining coextract fat is removed by a dispersive solid-phase extraction procedure [25-30]. The dispersive SPE sorbents such as $\mathrm{C}_{18}$, PSA (primary secondary amine), florisil, GCB (graphite carbon black), and a mixture of PSA/GCB $(3: 1 \mathrm{w} / \mathrm{w})$ were used in order to have a wider range of sorbent materials available for the performance of the pesticide residue determination with higher recoveries and lower fat levels transferred in the final extracts.

\section{Experimental Procedures}

2.1. Pesticide Standards, Reagents, and Samples. The analytical pesticide standards: simazine, terbuthylazine, atrazin, diuron, dimethoate, malathion, and carbaryl were obtained from Fluka (Buchs, Switzerland, HPLC grade 99.9\%). Individual pesticide stock solutions of the above analytes at $1.0 \mathrm{~m} \mathrm{~mL}^{-1}$ were prepared in pure methanol and kept in amber-coloured bottles at $4^{\circ} \mathrm{C}$. These solutions were kept for $2 \mathrm{~h}$ at ambient temperature prior to their use. The mixed standard-stock solution containing all of the studied pesticides was prepared by pooling aliquots of the individual pure pesticide standard solutions and then diluting with methanol. Working standard solutions of the mixture of pesticides (5 and $10 \mu \mathrm{g} \mathrm{mL}^{-1}$ ) were prepared by appropriate dilutions in methanol every day in order to avoid the influence on the results from the possible degradation of pesticides. HPLC grade acetonitrile $(\mathrm{MeCN})$, methanol $(\mathrm{MeOH})$ were purchased from Merck (Darmstadt, Germany). Reagent grade anhydrous magnesium sulphate, formic acid and Primary secondary amine (PSA) sorbent (SPE Bulk packing, $50 \mu \mathrm{m}$ ) were purchased from Sigma-Aldrich (Steinheim Loius, MO, USA). C18 sorbent $(50 \mu \mathrm{m})$ and graphitized carbon black (GCB) cartridges (SPE Bulk packing, 120-400 mesh) were obtained from Supelco (Bellefonte, PA, USA). A Milli-Q-Plus ultrapure water system from Millipore (Milford, MA) was used throughout the study to obtain the HPLC-grade water used during the analyses. As pretreatment prior to LC-TOFMS analysis, the extracted oil samples were merely filtered through a $0.45 \mu \mathrm{m}$ filter (Millex FG, Millipore, Milford, MA, USA). In this study, several samples of palm oil both from two different brands which were purchased from local supermarkets in Kuala Lumpur, Malaysia were sampled and analyzed following the purposed sample preparation methods for the determination of seven multiclass pesticide residues.

\subsection{Apparatus}

2.2.1. LC/Electrospray Quadrupole Time-of-Flight Mass Spectrometry. The separation of the selected pesticides was carried out using an HPLC system (consisting of a vacuum degasser, an autosampler, and a binary pump-SL; Agilent Technologies 1200 Series) equipped with a reversed phase resolution $\mathrm{C}_{18}$ analytical column of $50 \mathrm{~mm} \times 2.1 \mathrm{~mm}$, and $1.8 \mu \mathrm{m}$ particle size (Zorbax Eclipse SB- $\mathrm{C}_{18}$ ). Column temperature was maintained at $40^{\circ} \mathrm{C}$. The injected sample volume was $5 \mu \mathrm{L}$ in each study. In electrospray positive ionization mode, Mobile phase A and B were acetonitrile and water with $0.1 \%$ formic acid, respectively. The optimized chromatographic method held the initial mobile phase composition $(10 \% \mathrm{~A})$ constant for $5 \mathrm{~min}$, followed by a linear gradient to $100 \% \mathrm{~A}$ after $30 \mathrm{~min}$. The flow-rate was optimized at $0.25 \mathrm{~mL} / \mathrm{min}$. A $10-\mathrm{min}$ postrun time was used after each analysis. This HPLC system was connected to a time-of-flight mass spectrometer, Agilent MSD QTOF (Agilent Technologies, 6530 Accurate Mass QTOF), equipped with an electrospray interface operated in positive ion, using the following operation parameters: capillary voltage $4000 \mathrm{~V}$; nebulizer pressure $40 \mathrm{psig}$; drying gas $9 \mathrm{~L} / \mathrm{min}$; gas temperature $300^{\circ} \mathrm{C}$; fragmentor voltage (in source CID fragmentation) $190 \mathrm{~V}$; skimmer voltage $65 \mathrm{~V}$; octopole RF $750 \mathrm{~V}$. LC/MS accurate mass spectra were recorded across the range $50-1000 \mathrm{~m} / z$.

2.3. Spiking Procedures. For recovery studies, the samples were spiked with the studied pesticides before the corresponding extraction procedure. A representative $200 \mathrm{~g}$ portion of oil sample was weighed and fortified homogeneously with different volumes of working standard solution to obtain 
25,50 , and $100 \mathrm{ng} \mathrm{g}^{-1}$ of the studied pesticides in the spiked sample. The sample was incubated at room temperature for $6 \mathrm{~h}$ to make sure the solvent was completely evaporated.

2.4. Liquid-Liquid Extraction (LLE) Followed by Low-Temperature Precipitation (LTP). $3.00 \pm 0.01 \mathrm{~g}$ homogenous oil sample was weighted in a $50 \mathrm{~mL}$ screw-capped centrifuge tube. The sample was fortified when required, by pesticide standard mixture in $\mathrm{MeOH}$ to obtain concentration of $50 \mathrm{ng} \mathrm{g}^{-1}$. LLE was performed using $10 \mathrm{~mL} \mathrm{MeCN}$ as the extracting solvent. The mixture was then shaken for $10 \mathrm{~min}$ using a vortex mixer. After centrifugation at $3700 \mathrm{rpm}$ for $2 \mathrm{~min}$, the centrifuge tube was kept horizontally in a freezer at $-20^{\circ} \mathrm{C}$ for $2 \mathrm{~h}$. The organic phase containing the organic solvent and extracted pesticides remained as a liquid and rose to the top whereas the oil were frozen and precipitated at the bottom of the tube.

2.5. $d$-SPE Cleanup Procedure. Since fats are not very soluble in $\mathrm{MeCN}$, a certain quantity of them will be coextracted and these remaining matrix constituents would possibly interfere with the determination and deteriorate the LC-QTOF-MS system performance. Therefore, to solve this problem and to remove the remaining fat, an additional dispersive solidphase extraction (d-SPE) cleanup is necessary. Aliquots of the extract obtained from LTP were subjected to further cleanup by d-SPE procedure. Therefore, $5 \mathrm{~mL}$ of the obtained acetonitrile extract from the freezing-out step was separated from the precipitates by decantation and filtration then transferred into a $15-\mathrm{mL}$ microcentrifuge vial containing $100 \mathrm{mg}$ of anhydrous magnesium sulphate (to remove the residual water), $150 \mathrm{mg}$ of PSA sorbent (to remove various polar organic acids, polar pigments, some sugars, and fatty acids), $50 \mathrm{mg}$ of GCB sorbent (to remove sterols and pigments such as chlorophyll and beta-carotene). After shaking for $1 \mathrm{~min}$, the mixture in the tube was centrifuged at $3700 \mathrm{rpm}$ for $2 \mathrm{~min} .3 \mathrm{~mL}$ of the supernatant was then evaporated to slightly dryness and reconstituted with $1 \mathrm{~mL}$ to a final composition of $20 \% \mathrm{MeOH}$ in water. Then the extract was filtered through a $0.45 \mu \mathrm{m}$ PTFE filter prior to LC/MS analysis. Now the extract contained the equivalent of $1 \mathrm{~g}$ of sample per $\mathrm{mL}$. In order to obtain cleaner sample, the extract was diluted $1: 2$ prior to injection into LC-MS instrument. This step was carried out by taking up $500 \mu \mathrm{L}$ of the extract and adding $500 \mu \mathrm{L}$ of solvent $(20 \% \mathrm{MeOH})$. Finally, all samples contained $80 \%$ of water.

2.6. Validation Study. The use of matrix-matched standards provides reliable quantitation capabilities for food analyses [31]. For this purpose, the linearity of the method was studied through matrix matched calibration in triplicate at six concentrations in the range of $5-1000 \mathrm{ng} \mathrm{g}^{-1}$. Dilutions of standard solution of pesticides with the blank extract from the oil matrix extracted by purposed method were measured. An external calibration in the same concentrations was also performed by dilution of the standard of pesticides in methanol.

Accuracy (estimated by means of recovery experiments) and precision (expressed as repeatability in terms of relative standard deviation) were evaluated by analyzing palm oil sample spiked at three concentration levels $(25,50$, and $100 \mathrm{ng} \mathrm{g}^{-1}$ ). For this purpose, blank palm oil samples were fortified by adding a known volume of standard solution containing a mixture of pesticides in sample at the beginning of the process. Each fortification level was extracted in triplicate and injected three times $(n=9)$. The precision of the method was evaluated regarding the repeatability and the intermediate precision. Repeatability was studied with nine determinations, performing extraction of the sample by LLE/LTP and d-SPE cleanup procedure in three different fortification levels, in triplicate. Intermediate precision was estimated as repeatability, but on different days and by different analysts.

The instrumental limit of detection (LOD) and limit of quantitation (LOQ) were determined from the injection of matrix-matched standard solutions with low concentration levels giving a signal-to-noise ratio of 3 and 10, respectively.

Matrix effect can reduce or enhance the response of the detector and it can be evaluated by comparing the detector response for pesticide standards prepared in solvent with that for standards prepared in sample extract. In this study, these possible effects were evaluated by comparing the slopes obtained in the calibration with matrix-matched standards and those obtained with solvent-based standards, to calculate matrix slope/solvent slope ratio for each pesticide. A value $<1$ indicates signal suppression due to the matrix, while values $>$ 1 involve enhancing effect of the matrix on analyte signal. Regarding to the obtained result, quantitation of pesticides was performed with matrix-matched calibration, using the same matrix as the sample analyzed.

\section{Results and Discussion}

3.1. Identification and Confirmation of the Targeted Pesticides by LC-QTOF-MS: in-Source CID Fragmentation and Accurate Mass Measurements. Standard electrospray ionization conditions were selected to achieve the best possible sensitivity and selectivity for the selected compounds. Standard values were set for nitrogen flow rates, capillary voltage, and vaporizer and drying gas temperatures. Besides the typical electrospray parameters, the parameter associated with insource collision induced dissociation (CID) fragmentation (Fragmentor voltage) which had a strong influence on the sensitivity and relative abundance of protonated molecules were carefully studied. The identification of the targeted species was performed basically by retention time matching combined with accurate mass spectrum features of each compound and, when available, their main fragment ions and or isotope signature (i.e., ${ }^{37} \mathrm{Cl}$ ). For this purpose, narrow mass window extracted ion chromatograms were used.

The signal-intensity pattern of the ${ }^{37} \mathrm{Cl}$ isotope signal evidences that the peak contains chlorine atom unequivocally. In addition, the relative abundance of the isotopic signal for ${ }^{37} \mathrm{Cl}$ will suggest whether the compound contains a unique chlorine atom such in the case of simazine, terbuthylazine, and atrazine or two atoms as in the case of diuron. Besides the usefulness of the chlorine isotopic profiles in this sense, the accurate mass obtained for the ${ }^{37} \mathrm{Cl}$ isotope, which is 


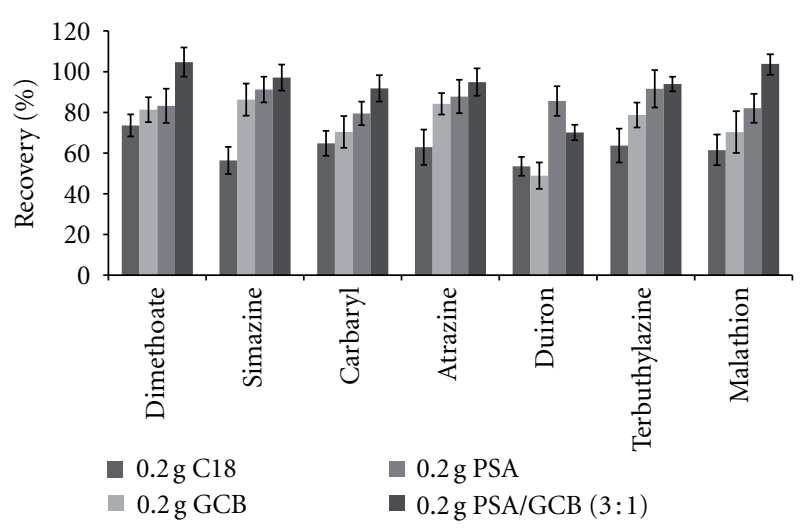

FIGURE 1: Mean percent recovery and RSD (\%) of the studied pesticides in palm oil sample using LLE/LTP and d-SPE procedure with different cleanup sorbents.

the one of the characteristic features of time-of-flight when applied to halogen-containing pesticides, is useful. Therefore, the accurate mass of each protonated molecule along with the characteristic fragment ion, the corresponding generated elemental compositions, the presence of the chlorine signature, and the characteristic retention time represent enough information to unequivocally identify and confirm members of this class of pesticides in such complicated matrices. The combination of in-source CID and the comparison and evaluation of the theoretical and experimental isotope patterns (from the elemental composition of the species) are powerful tools for identification purposes in most of the targeted species. The accurate mass of characteristic isotopic signals, and the distance in the $\mathrm{m} / z$ axis between them can be combined by the software to provide a user-created weighted coefficient estimating how similar the experimental mass spectrum is when compared to that obtained with standards. Table 1 shows the results obtained for the accurate mass analysis of the selected pesticides in a matrix-matched standard, spiked at $50 \mathrm{ng} \mathrm{g}^{-1}$. As a result, more accurate mass information was obtained for both protonated molecules, which consisted of chlorine ${ }^{35} \mathrm{Cl}$ and chlorine ${ }^{37} \mathrm{Cl}$ isotope. Simazine, terbuthylazine, and atrazine have one chlorine atom however diuron contains two chlorine atoms, so we can get up three ions and their respective accurate masses in this study, which is much wider information than that obtained from single quad and selected ion monitoring techniques. As can be seen in Table 1, no significant difference was observed in the mass accuracy obtained in the matrix-matched standards when compared with that obtained with standards in pure solvent. Therefore, we can deduce that the method offers a high degree of confirmation because of its very high mass accuracy, enabling accurate mass measurements of target ions within $2 \mathrm{ppm}$ error in most cases.

3.2. Optimization Approach of $d$-SPE Cleanup. In this method after LLE and freezing-out step and separation of the solvent and oil as described in Section 2.4, aliquots of the obtained acetonitrile extract from the LTP step was subjected

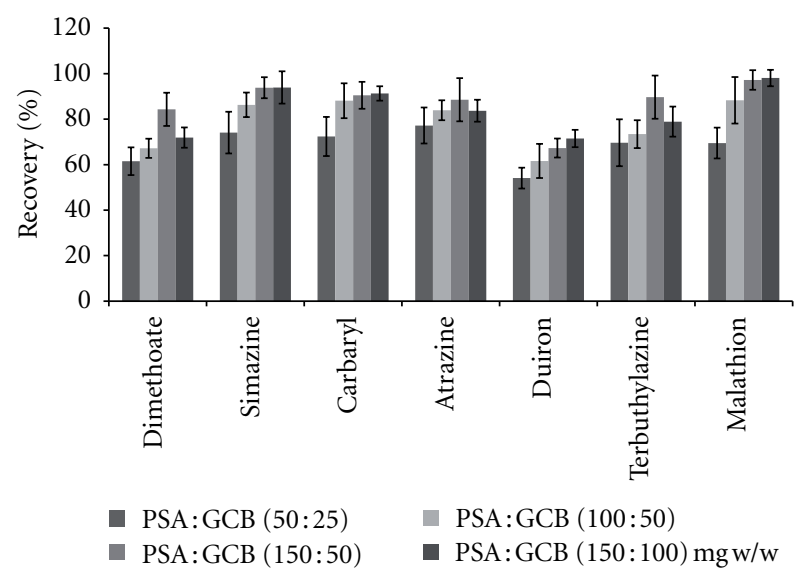

FIGURE 2: Effect of GCB content in the cleanup sorbents (PSA/GCB $\mathrm{w} / \mathrm{w}$ ) on the extraction efficiency of pesticides studied in palm oil using d-SPE procedure.

to d-SPE cleanup procedure. The sorbent has a fundamental role in d-SPE: it promotes the rupture of the physical structure of the sample and adsorbs the matrix compounds [31]. In this case, different sorbents such as $200 \mathrm{mg} \mathrm{C} 18,200 \mathrm{mg}$ GCB, $200 \mathrm{mg}$ PSA, and a bulk of sorbent of $150 \mathrm{mg}$ PSA and $50 \mathrm{mg}$ GCB were evaluated in order to find out materials available for the performance of the pesticides determination with higher recoveries and lower fat levels transferred in the final extracts. The palm oil samples spiked at $50 \mathrm{ng} \mathrm{g}^{-1}$ were applied for all optimization purposes. The extracts were analyzed in triplicates measurements and injected three times $(n=9)$. The respective mean recoveries of studied pesticides are shown in Figure 1. As we can see, the respective mean of recoveries of the pesticides determined by LC-QTOF-MS ranged from 53.5 to $73.6 \%$ for cleanup on $\mathrm{C} 18$, from 70.4 to $86.3 \%$ for cleanup on GCB except diuron (48.9\%), from 79.5 to $91.6 \%$ for cleanup on PSA and from 91.8 to $104.7 \%$ for cleanup on bulk of PSA and GCB except in the case of diuron (70.1\%). C18 is the sorbent which is widely used for different applications of d-SPE and MSPD procedures to extract polar moderate compounds [32-34]. C18 as cleanup sorbent resulted in the chromatogram with higher background and interfering peaks from the palm oil. GCB has a strong affinity for planar molecules, and thus effectively removes pigments such as chlorophyll and carotenoids, as well as sterols present in foods [29]. The obtained low recovery for diuron when GCB was used as a dispersant indicated that, this compound was not completely retained in the GCB phase during the cleanup procedure, it can be explained due to its planar structure. PSA is known to exhibit a strong retaining activity for sugars, fatty acids, and other organic acids. All pesticides assayed fell within the acceptable recoveries with RSD values below $8.5 \%$ when a bulk of PSA and GCB were used as the cleanup sorbent. Although d-SPE cleanup on PSA gave clean chromatogram from the extract, however, a bulk of PSA and GCB $(3: 1 \mathrm{w} / \mathrm{w})$ showed the cleanest chromatogram from the extract with lowest interfering and gave the highest mean recoveries from 91.8 to $104.7 \%$. These mixed sorbents also presented better recoveries and lower 
TABLE 1: The mean retention times $\left(t_{R}\right)$ with RSD (\%) and LC-QTOF-MS accurate mass measurements of the protonated molecules and the main fragment ions of the pesticides studied in the matrix-matched standard (fragmentor voltage $190 \mathrm{~V}$, spiking level: $50 \mathrm{ng} \mathrm{g}^{-1}$ ).

\begin{tabular}{|c|c|c|c|c|c|c|c|}
\hline \multirow{2}{*}{ Analyte } & \multirow{2}{*}{$t_{R}^{\mathrm{a}}(\min )$} & \multirow{2}{*}{ RSD (\%) } & \multirow{2}{*}{ Elemental composition } & \multirow{2}{*}{ Theoritical $\mathrm{m} / \mathrm{z}$} & \multirow{2}{*}{ Experimental $\mathrm{m} / \mathrm{z}$} & \multicolumn{2}{|c|}{ Error } \\
\hline & & & & & & $\mathrm{mDa}$ & ppm \\
\hline \multirow{5}{*}{ Dimethoate } & \multirow{5}{*}{13.91} & \multirow{5}{*}{1.13} & $\mathrm{C}_{5} \mathrm{H}_{13} \mathrm{NO}_{3} \mathrm{PS}_{2}$ & 230.0069 & 230.0071 & 0.2 & 0.87 \\
\hline & & & $\mathrm{C}_{4} \mathrm{H}_{8} \mathrm{O}_{3} \mathrm{PS}_{2}$ & 198.9885 & 198.9879 & -0.6 & -3.01 \\
\hline & & & $\mathrm{C}_{3} \mathrm{H}_{7} \mathrm{O}_{2} \mathrm{PS}_{2}$ & 170.9698 & 170.9693 & -0.5 & -2.92 \\
\hline & & & $\mathrm{C}_{2} \mathrm{H}_{6} \mathrm{O}_{2} \mathrm{PS}$ & 124.9821 & 124.9825 & 0.4 & 3.20 \\
\hline & & & $\mathrm{C}_{5} \mathrm{H}_{12} \mathrm{NO}_{3} \mathrm{PS}_{2} \mathrm{Na}$ & 251.9888 & 251.9894 & 0.6 & 2.38 \\
\hline \multirow{4}{*}{ Simazine } & \multirow{4}{*}{17.07} & \multirow{4}{*}{1.02} & $\mathrm{C}_{7} \mathrm{H}_{13} \mathrm{~N}_{5}^{35} \mathrm{Cl}$ & 202.0854 & 202.0859 & 0.5 & 2.47 \\
\hline & & & $\mathrm{C}_{7} \mathrm{H}_{13} \mathrm{~N}_{5}{ }^{37} \mathrm{Cl}$ & 204.0824 & 204.0827 & 0.3 & 1.47 \\
\hline & & & $\mathrm{C}_{5} \mathrm{H}_{9} \mathrm{~N}_{5}{ }^{35} \mathrm{Cl}$ & 174.0541 & 174.0542 & 0.1 & 0.57 \\
\hline & & & $\mathrm{C}_{4} \mathrm{H}_{7} \mathrm{~N}_{3}{ }^{35} \mathrm{Cl}$ & 132.0323 & 132.0324 & 0.1 & 0.75 \\
\hline \multirow{2}{*}{ Carbaryl } & \multirow{2}{*}{19.38} & \multirow{2}{*}{0.84} & $\mathrm{C}_{12} \mathrm{H}_{12} \mathrm{NO}_{2}$ & 202.0863 & 202.0863 & 0.0 & $\overline{-0.1}$ \\
\hline & & & $\mathrm{C}_{10} \mathrm{H}_{9} \mathrm{O}$ & 145.0648 & 145.0654 & 0.6 & 4.13 \\
\hline \multirow{3}{*}{ Atrazine } & \multirow{3}{*}{19.41} & \multirow{3}{*}{0.61} & $\mathrm{C}_{8} \mathrm{H}_{15} \mathrm{~N}_{5}{ }^{35} \mathrm{Cl}$ & 216.1010 & 216.1016 & 0.5 & 2.32 \\
\hline & & & $\mathrm{C}_{8} \mathrm{H}_{15} \mathrm{~N}_{5}{ }^{37} \mathrm{Cl}$ & 218.0980 & 218.0982 & 0.2 & 0.92 \\
\hline & & & $\mathrm{C}_{5} \mathrm{H}_{9} \mathrm{~N}_{5}{ }^{35} \mathrm{Cl}$ & 174.0541 & 174.0540 & -0.1 & -0.57 \\
\hline \multirow{5}{*}{ Diuron } & \multirow{5}{*}{19.98} & \multirow{5}{*}{1.85} & $\mathrm{C}_{9} \mathrm{H}_{11} \mathrm{~N}_{2} \mathrm{O}^{35} \mathrm{Cl}_{2}$ & 233.0243 & 233.0243 & $\begin{array}{l}-0.1 \\
\end{array}$ & -0.43 \\
\hline & & & $\mathrm{C}_{9} \mathrm{H}_{11} \mathrm{~N}_{2} \mathrm{O}^{35} \mathrm{Cl}^{37} \mathrm{Cl}$ & 235.0213 & 235.0214 & 0.1 & 0.42 \\
\hline & & & $\mathrm{C}_{9} \mathrm{H}_{11} \mathrm{~N}_{2} \mathrm{O}^{37} \mathrm{Cl}_{2}$ & 237.0183 & 237.0189 & 0.6 & 2.53 \\
\hline & & & $\mathrm{C}_{9} \mathrm{H}_{10} \mathrm{~N}_{2} \mathrm{OCl}_{2} \mathrm{Na}$ & 255.0062 & 255.0059 & -0.3 & -1.17 \\
\hline & & & $\mathrm{C}_{3} \mathrm{H}_{6} \mathrm{NO}$ & 72.0444 & 72.0447 & 0.3 & 4.16 \\
\hline \multirow{3}{*}{ Terbuthylazine } & \multirow{3}{*}{22.19} & \multirow{3}{*}{0.92} & $\mathrm{C}_{9} \mathrm{H}_{17} \mathrm{~N}_{5}{ }^{35} \mathrm{Cl}$ & 230.1167 & 230.1169 & 0.2 & 0.87 \\
\hline & & & $\mathrm{C}_{9} \mathrm{H}_{17} \mathrm{~N}_{5}{ }^{37} \mathrm{Cl}$ & 232.1137 & 232.1138 & 0.1 & 0.43 \\
\hline & & & $\mathrm{C}_{5} \mathrm{H}_{9} \mathrm{~N}_{5}{ }^{35} \mathrm{Cl}$ & 174.0541 & 174.0543 & 0.2 & 1.15 \\
\hline \multirow{4}{*}{ Malathion } & \multirow{4}{*}{22.23} & \multirow{4}{*}{1.90} & $\mathrm{C}_{10} \mathrm{H}_{20} \mathrm{O}_{6} \mathrm{PS}_{2}$ & 331.0433 & 331.0429 & -0.4 & -1.21 \\
\hline & & & $\mathrm{C}_{10} \mathrm{H}_{19} \mathrm{O}_{6} \mathrm{PS}_{2} \mathrm{Na}$ & 353.0253 & 353.0259 & 0.6 & 1.70 \\
\hline & & & $\mathrm{C}_{8} \mathrm{H}_{14} \mathrm{O}_{5} \mathrm{PS}_{2}$ & 285.0015 & 285.0014 & -0.1 & -0.35 \\
\hline & & & $\mathrm{C}_{2} \mathrm{H}_{8} \mathrm{O}_{2} \mathrm{PS}$ & 128.0055 & 128.0051 & -0.3 & -2.34 \\
\hline
\end{tabular}

${ }^{\mathrm{a}} n=20$.

RSDs\% which are between 3.8 and $6.5 \%$ in relation to the other solid supports. To assay the effect of GCB content in the cleanup sorbent on d-SPE efficiency, a mixture of PSA/GCB at ratios 25,50 , and 100 of GCB were investigated. The results obtained are shown in Figure 2. The recoveries of pesticides studied increased with an increase in GCB up to $50 \%$. No significant changes were observed with an increase in the content of GCB in most cases. Therefore, the extracts obtained using PSA/GCB at ratio $3: 1 \mathrm{w} / \mathrm{w}$ furnished a transparent and colorless solution with minimal interferences for pesticides studied. In all subsequent experiments, $150 \mathrm{mg}$ of PSA and $50 \mathrm{mg}$ of PSA: GCB $(3: 1 \mathrm{w} / \mathrm{w})$ were used as sufficient cleanup adsorbent, respectively. Comparative study between two chromatograms obtained from the extracts after only freezing-out cleanup and additional d-SPE showed some chromatographic problems such as peak suppression of dimethoate and retention time shifts of dimethoate, simazine, and malathion. The typical chromatogram obtained by LCQTOF-MS of the spiked palm oil and blank palm oil extracted using LTP followed by d-SPE procedure have been shown in Figure 3.

\subsection{Method Validation}

3.3.1. Precision and Accuracy. Once the parameters that affect the LLE/LTP and d-SPE cleanup procedure were optimized, a method validation process was performed by establishing the basic analytical requirements of the performance to be appropriate for quantitative determination of selected pesticides in oil samples. To evaluate the effectiveness of the extraction method, recovery studies were carried out by spiking of samples at three different concentration levels: 25, 50, and $100 \mathrm{ng} \mathrm{g}^{-1}$. Each fortification level was extracted in triplicate and injected three times $(n=9)$ to determine the mean recovery (\%) and relative standard deviation (RSD \%). Table 2 shows the mean recoveries and RSD of the repeatability and inter mediate precision for the different concentration levels. Most values of the relative standard deviations of the analyzed samples were in general less than $10 \%$ that could be attributed to the experimental error. The mean recoveries ranged from $71.8 \%$ and $112.4 \%$ with RSD from $3.2 \%$ to $15.1 \%$ which are suitable for the determination of pesticide residues.

3.3.2. Linearity, Detection, and Quantification Limits. The detector response was linear within the concentration range studied. Linearity for all compounds was determined using blank palm oil samples fortified at concentration levels ranging 5 to $1000 \mathrm{ng} \mathrm{g}^{-1}$. The slope and intercept values, together with their standard deviations, were estimated using regression analyses. The responses of all compounds 


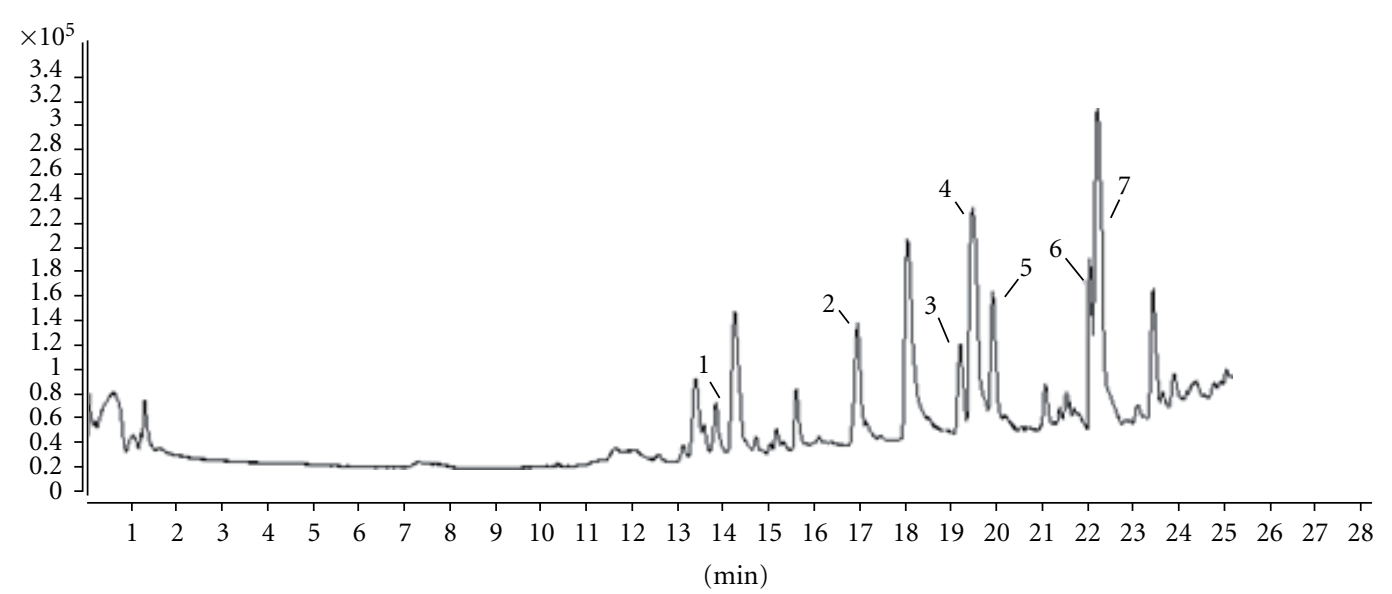

(a)

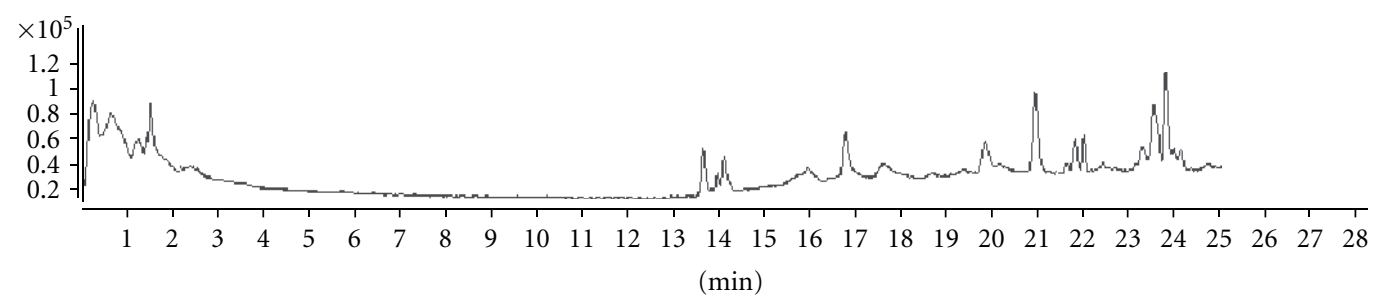

(b)

FIGURE 3: (a)Total-ion chromatogram (TIC) corresponding to the LC-QTOF-MS analysis of palm oil sample spiked with 50 ng kg ${ }^{-1}$ of pesticides. (b) Typical Chromatograms obtained by LC-QTOF-MS of blank palm oil extract sample.

TABLE 2: Mean recovery, repeatability $\left(\mathrm{RSD}_{\mathrm{r}}\right)$, and intermediate precision $\left(\mathrm{RSD}_{\mathrm{ip}}\right)$ of the method for the mixture of the compounds in palm oil spiked at different levels.

\begin{tabular}{|c|c|c|c|}
\hline Pesticide & Concentration level $\left(\mathrm{ngg}^{-1}\right)$ & Mean rec $\pm \operatorname{RSD}_{\mathrm{r}}(\%)^{\mathrm{a}}$ & Mean rec $\pm \mathrm{RSD}_{\text {ip }}(\%)^{\mathrm{a}}$ \\
\hline \multirow{3}{*}{ Dimethoate } & 25 & $73.5 \pm 4.9$ & $71.8 \pm 6.5$ \\
\hline & 50 & $82.2 \pm 10.3$ & $84.4 \pm 9.7$ \\
\hline & 100 & $80.7 \pm 7.1$ & $87.8 \pm 11.2$ \\
\hline \multirow{3}{*}{ Simazine } & 25 & $83.4 \pm 3.2$ & $89.6 \pm 9.1$ \\
\hline & 50 & $104.6 \pm 7.7$ & $107.6 \pm 9.8$ \\
\hline & 100 & $91.1 \pm 5.8$ & $110.5 \pm 8.9$ \\
\hline \multirow{3}{*}{ Carbaryl } & 25 & $77.2 \pm 13.3$ & $75.7 \pm 6.2$ \\
\hline & 50 & $89.1 \pm 8.0$ & $87.3 \pm 12.5$ \\
\hline & 100 & $93.4 \pm 5.7$ & $92.9 \pm 9.6$ \\
\hline \multirow{3}{*}{ Atrazine } & 25 & $73.3 \pm 5.4$ & $82.9 \pm 8.5$ \\
\hline & 50 & $95.8 \pm 8.8$ & $105.9 \pm 15.1$ \\
\hline & 100 & $87.2 \pm 10.4$ & $112.4 \pm 10.2$ \\
\hline \multirow{3}{*}{ Diuron } & 25 & $61.3 \pm 8.1$ & $58.5 \pm 6.2$ \\
\hline & 50 & $64.7 \pm 3.4$ & $71.2 \pm 8.8$ \\
\hline & 100 & $76.4 \pm 6.4$ & $73.4 \pm 11.3$ \\
\hline \multirow{3}{*}{ Terbuthylazine } & 25 & $71.8 \pm 6.2$ & $80.6 \pm 7.3$ \\
\hline & 50 & $91.1 \pm 7.9$ & $96.6 \pm 11.4$ \\
\hline & 100 & $85.3 \pm 11.5$ & $91.7 \pm 13.5$ \\
\hline \multirow{3}{*}{ Malathion } & 25 & $79.2 \pm 5.8$ & $74.4 \pm 7.2$ \\
\hline & 50 & $109.4 \pm 3.2$ & $92.8 \pm 10.3$ \\
\hline & 100 & $106.7 \pm 10.2$ & $93.5 \pm 9.4$ \\
\hline
\end{tabular}

${ }^{\mathrm{a}} n=9$. 
TABLE 3: Calibration data, matrix effects expressed as the average standard deviation (RSD \%) and the ratio between the calibration curve slopes of matrix-matched standards and solvent-based standards, LOD and LOQ of the pesticides analysed in palm oil samples by LC-QTOFMS.

\begin{tabular}{|c|c|c|c|c|c|c|c|c|c|}
\hline \multirow{2}{*}{ Pesticide } & \multicolumn{2}{|c|}{ Solvent } & \multicolumn{2}{|c|}{ Matrix } & \multirow[b]{2}{*}{$\operatorname{ME}(\Delta \%)$} & \multirow[b]{2}{*}{$\operatorname{LOD}\left(\operatorname{ng~g}^{-1}\right)$} & \multirow[b]{2}{*}{ LOQ $\left(\mathrm{ng} \mathrm{g}^{-1}\right)$} & \multirow[b]{2}{*}{${ }^{*} \operatorname{MRL}\left(\mathrm{ng} \mathrm{g}^{-1}\right)$} & \multirow[b]{2}{*}{ Residues found ( $\mathrm{ng} \mathrm{g}^{-1}$ ) } \\
\hline & Slope & $R^{2}$ & Slope & $R^{2}$ & & & & & \\
\hline Dimethoate & 18194 & 0.9989 & 11352 & 0.9992 & $0.62(-37.6)$ & 2.0 & 6.1 & 50 & 6.5 \\
\hline Simazine & 10474 & 0.9994 & 10876 & 0.9990 & $1.04(+3.8)$ & 2.7 & 8.2 & n.r & n.d \\
\hline Carbaryl & 63523 & 0.9996 & 69046 & 0.9989 & $1.08(+8.7)$ & 2.0 & 6.1 & 25000 & n.d \\
\hline Atrazine & 22762 & 0.9984 & 21574 & 0.9988 & $0.94(-5.2)$ & 1.5 & 4.6 & n.r & n.d \\
\hline Diuron & 22563 & 0.9993 & 27595 & 0.9987 & $1.22(+22.3)$ & 0.8 & 2.1 & 200 & n.d \\
\hline Terbuthylazine & 41022 & 0.9995 & 46485 & 0.9992 & $1.13(+13.3)$ & 1.0 & 3.0 & n.r & n.d \\
\hline Malathion & 12050 & 0.9993 & 12411 & 0.9990 & $0.82(-17.5)$ & 1.1 & 3.1 & 500 & 3.5 \\
\hline
\end{tabular}

${ }^{*}$ MRL for pesticides in palm oil [5].

n.r: not reported.

n.d: not detected.

extracted with purposed method were linear in the range under study with the regression coefficients higher than 0.9983. Detection and quantification limits were experimentally calculated from the injection of matrix-matched standard solutions at low concentration levels, using the more abundant ion for each compound based on the signal from high-resolution extracted ion chromatograms with narrow mass windows. The LOD and the LOQ values for pesticides, and the data of linear regression are shown in Table 3. The LOD and LOQ were in the range of $0.8-2.7 \mathrm{ng} \mathrm{g}^{-1}$ and $2.1-8.2 \mathrm{ng} \mathrm{g}^{-1}$, respectively. They were all satisfactory, lower than the maximum residue limits (MRLs) accepted by National Committee on Agricultural Commodity and Food Standards issued published by Thai Agricultural Standards on Pesticide Residues [5]. These results demonstrate the high sensibility of the proposed method based on LLE/LTP followed by d-SPE cleanup and LC-QTOF-MS for the detection and quantification of the selected pesticides in palm oil.

3.3.3. Matrix Effect Study. Matrix components can provide variation in the detector response to pesticides. Matrix components can both reduce or enhance the signal given by the analytes when they achieve the detector. The problem is originated in the interface (source) when the matrix constituents influence the ionization of a coeluted analyte, causing ion suppression. The sample treatment protocol was designed aiming at minimizing the potential matrix effects, using a reduced preconcentration factor. The impact of the matrix on the ionization suppression/enhancement on the analytes (compared to neat standards) can be evaluated by comparing the detector response for pesticide standards prepared in solvent with that for standards prepared in sample extract. In this study, these possible effects were evaluated by comparing the slopes obtained in the calibration with matrix-matched standards and those obtained with solvent-based standards, calculating matrix slope/solvent slope ratio for each pesticide. The results are summarized in Table 3. The percentages of signal suppression or enhancement (calculated by formula: matrix slope/solvent slope ratio $\times 100-100)$ are also shown in this table. Negative values indicate signal suppression of the matrix, while positive results show enhancement due to the matrix. The obtained positive values in more cases showed an enhancement signal for palm oil extracts except dimethoate, atrazine, and malathion that indicated signal suppression. The compound dimethoate presented \%ME of $-37.6 \%$, indicating that the compound suffers ionization suppression, probably due to the presence of sulfur compounds in the sample. These compounds elute in the same retention time of analyte, and compete with the compound during the ionization process [35-39]. As a result, no significant matrix effects were observed more than $\pm 20 \%$ signal enhancement and suppression in most cases except diuron $(+22.3 \%)$ and dimethoate $(-37.6 \%)$. Therefore, quantitation of pesticides was performed with matrix-matched calibration, using the same matrix as the sample analyzed.

3.4. Determination of Pesticides in Market-Purchased Palm Oil Samples. The proposed method was applied to the analysis of two different brands of market purchased palm oil samples collected from Kuala Lumpur city of Malaysia. The positive findings of the detected pesticides were confirmed by LC-QTOF-MS accurate mass analysis (obtaining mass accuracy $<2$ ppm error in most cases), thus showing the usefulness of LC-QTOF-MS for the multiresidue analysis of pesticides in palm oil samples. A concentration of $6.5 \mathrm{ng} \mathrm{g}^{-1}$ of dimethoate and $3.5 \mathrm{ngg}^{-1}$ of malathion were present in the palm oil samples. The results obtained are shown in Table 3. The results showed that, no pesticide residues were found at concentrations above the permitted MRL for pesticide residues published by the National Committee on Agricultural Commodity and Food Standards for palm oil. The results show the ability of the proposed method for pesticide testing and quantitation palm oil samples at low concentration levels. 


\section{Conclusions}

The development of sample-treatment methodologies for the determination of pesticide residues in matrices with high fat content (such as palm oil) is a demanding task, since even small amounts of coextracted fat can irreversibly damage the chromatographic column. In the present work, an efficient, easy, economical, rugged, and environmental friendly multiresidue method based on acetonitrile extraction coupled with freezing and d-SPE cleanup was successfully evaluated to determine seven multiclass pesticides in palm oil. The optimized method, involving LC-QTOF-MS, offers high recovery and low detection and quantification limits for all compounds, since it is simple, fast, and inexpensive. The results shown that the sensitivity obtained with the proposed method is appropriate for the multiresidue analysis of pesticides in the tested samples. The performance of the method was very satisfactory with results meeting validation criteria. For quantitative evaluation, matrix effects were evaluated by comparing the slopes of the matrix-matched and solventbased calibration curves. The minor effects were observed by most of pesticides studied. The potential of the proposed method was demonstrated by analyzing two brands market purchased samples with excellent selectivity and sensitivity.

\section{References}

[1] A. S. H. Ong and S. H. Goh, "Palm oil: a healthful and costeffective dietary component," Food and Nutrition Bulletin, vol. 23, no. 1, pp. 11-22, 2002.

[2] R. P. Z. Furlani, K. M. Marcilio, F. M. Leme, and S. A. V. Tfouni, "Analysis of pesticide residues in sugarcane juice using QuEChERS sample preparation and gas chromatography with electron capture detection," Food Chemistry, vol. 126, no. 3, pp. 1283-1287, 2011.

[3] Y. Picó, C. Blasco, and G. Font, "Environmental and food applications of LC-tandem mass spectrometry in pesticideresidue analysis: an overview," Mass Spectrometry Reviews, vol. 23, no. 1, pp. 45-85, 2004.

[4] Codex Alimentarius Commission, Codex Alimentarius Pesticide Residues in Food Maximum Residues Limits, vol. 2, FHO/WHO, Rome, Italy, 2nd edition, 1996.

[5] Thai Agricultural Standard (TAS 9002-2008), Published in the Royal Gazette Vol. 125 Special Section 139D, dated 18 August B.E. 2551, 2008.

[6] Y. Picó, G. Font, M. J. Ruiz, and M. Fernández, "Control of pesticide residues by liquid chromatography-mass spectrometry to ensure food safety," Mass Spectrometry Reviews, vol. 25, no. 6, pp. 917-960, 2006.

[7] C. Soler and Y. Picó, "Recent trends in liquid chromatographytandem mass spectrometry to determine pesticides and their metabolites in food," TrAC Trends in Analytical Chemistry, vol. 26, no. 2, pp. 103-115, 2007.

[8] L. Alder, K. Greulich, G. Kempe, and B. Vieth, "Residue analysis of 500 high priority pesticides: better by GC-MS or LC-MS/MS?" Mass Spectrometry Reviews, vol. 25, no. 6, pp. 838-865, 2006.

[9] A. R. Fernández-Alba, Chromatographic-Mass Spectrometric Food Analysis For Trace Determination of Pesticide Residues, Elsevier, 2005.
[10] F. Hernández, O. J. Pozo, J. V. Sancho, L. Bijlsma, M. Barreda, and E. Pitarch, "Multiresidue liquid chromatography tandem mass spectrometry determination of 52 non gas chromatography-amenable pesticides and metabolites in different food commodities," Journal of Chromatography A, vol. 1109, no. 2, pp. 242-252, 2006.

[11] S. Lacorte and A. R. Fernández-Alba, "Time of flight mass spectrometry applied to the liquid chromatographic analysis of pesticides in water and food," Mass Spectrometry Reviews, vol. 25, no. 6, pp. 866-880, 2006.

[12] J. F. García-Reyes, M. D. Hernando, A. Molina-Díaz, and A. R. Fernández-Alba, "Comprehensive screening of target, nontarget and unknown pesticides in food by LC-TOF-MS," TrAC Trends in Analytical Chemistry, vol. 26, no. 8, pp. 828-841, 2007.

[13] I. Ferrer, J. F. García-Reyes, and A. Fernández-Alba, "Identification and quantitation of pesticides in vegetables by liquid chromatography time-of-flight mass spectrometry," TrAC Trends in Analytical Chemistry, vol. 24, no. 7, pp. 671-682, 2005.

[14] Ch. Lentza-Rizos, E. J. Avramides, and F. Cherasco, "Lowtemperature clean-up method for the determination of organophosphorus insecticides in olive oil," Journal of Chromatography A, vol. 912, no. 1, pp. 135-142, 2001.

[15] M. Guardia-Rubio, A. Ruiz-Medina, A. Molina-Díaz, and M. J. Ayora-Cañada, "Influence of harvesting method and washing on the presence of pesticide residues in olives and olive oil," Journal of Agricultural and Food Chemistry, vol. 54, no. 22, pp. 8538-8544, 2006.

[16] E. Fuentes, M. E. Báez, and A. Quiñones, "Suitability of microwave-assisted extraction coupled with solid-phase extraction for organophosphorus pesticide determination in olive oil," Journal of Chromatography A, vol. 1207, no. 1-2, pp. 38-45, 2008.

[17] Sh. Chen, X. Yu, X. He, D. Xie, Y. Fan, and J. Peng, "Simplified pesticide multiresidues analysis in fish by low-temperature cleanup and solid-phase extraction coupled with gas chromatography/mass spectrometry," Food Chemistry, vol. 113, no. 4, pp. 1297-1300, 2009.

[18] J. F. García-Reyes, C. Ferrer, E. M. Thurman, A. R. FernándezAlba, and I. Ferrer, "Analysis of herbicides in olive oil by liquid chromatography time-of-flight mass spectrometry," Journal of Agricultural and Food Chemistry, vol. 54, no. 18, pp. 6493-6500, 2006.

[19] L. M. Ravelo-Pérez, J. Hernández-Borges, T. M. Borges-Miquel, and M. A. Rodríguez-Delgado, "Solid-phase microextraction and sample stacking micellar electrokinetic chromatography for the analysis of pesticide residues in red wines," Food Chemistry, vol. 111, no. 3, pp. 764-770, 2008.

[20] M. L. Hopper, "Automated one-step supercritical fluid extraction and clean-up system for the analysis of pesticide residues in fatty matrices," Journal of Chromatography A, vol. 840, no. 1, pp. 93-105, 1999.

[21] N. Motohashi, H. Nagashima, and C. Parkanyi, "Supercritical fluid extraction for the analysis of pesticide residues in miscellaneous samples," Journal of Biochemical and Biophysical Methods, vol. 43, no. 1-3, pp. 313-328, 2000.

[22] H. Muhamad, M. Pauzi Abdullah, Y. A. Tan, and S. C. Soh, "Optimization of the sweep co-distillation clean-up method for the determination of organochlorine pesticide residues in palm oil," Journal of Oil Palm Research, vol. 16, no. 2, pp. 30-36, 2004.

[23] C. B. Yeoh, A. Kuntom, S. Dorasamy, M. R. Omar, M. Y. M. Nor, and M. R. M. Noh, "Determination of acephate, methamidophos and monocrotophos in crude palm oil," European Journal 
of Lipid Science and Technology, vol. 108, no. 11, pp. 960-964, 2006.

[24] H. Muhamad, Y. A. Tan, and S. Ismail, "Determination of the herbicide fluroxypyr in oil matrices," Journal of Environmental Science and Health B, vol. 43, no. 2, pp. 134-140, 2008.

[25] M. Anastassiades, S. J. Lehotay, D. Štajnbaher, and F. J. Schenck, "Fast and easy multiresidue method employing acetonitrile extraction/partitioning and "dispersive solid-phase extraction" for the determination of pesticide residues in produce," Journal of AOAC International, vol. 86, no. 2, pp. 412-431, 2003.

[26] S. J. Lehotay, K. Maštovská, and S. J. Yun, "Evaluation of two fast and easy methods for pesticide residue analysis in fatty food matrixes," Journal of AOAC International, vol. 88, no. 2, pp. 630-638, 2005.

[27] S. J. Lehotay, K. Maštovská, and A. R. Lightfield, "Use of buffering and other means to improve results of problematic pesticides in a fast and easy method for residue analysis of fruits and vegetables," Journal of AOAC International, vol. 88, no. 2, pp. 615-629, 2005.

[28] S. J. Lehotay, A. Kok, M. Hiemstra, and P. van Bodegraven, "Validation of a fast and easy method for the determination of residues from 229 pesticides in fruits and vegetables using gas and liquid chromatography and mass spectrometric detection," Journal of AOAC International, vol. 88, no. 2, pp. 595-614, 2005.

[29] M. Anastassiades, K. Maštovská, and S. J. Lehotay, "Evaluation of analyte protectants to improve gas chromatographic analysis of pesticides," Journal of Chromatography A, vol. 1015, no. 1-2, pp. 163-184, 2003.

[30] T. D. Nguyen, B. S. Lee, B. R. Lee, D. M. Lee, and G. H. Lee, "A multiresidue method for the determination of 109 pesticides in rice using the Quick Easy Cheap Effective Rugged and Safe (QuEChERS) sample preparation method and gas chromatography/mass spectrometry with temperature control and vacuum concentration," Rapid Communications in Mass Spectrometry, vol. 21, no. 18, pp. 3115-3122, 2007.

[31] S. A. Rodrigues, S. S. Caldas, and E. G. Primel, "A simple; efficient and environmentally friendly method for the extraction of pesticides from onion by matrix solid-phase dispersion with liquid chromatography-tandem mass spectrometric detection," Analytica Chimica Acta, vol. 678, no. 1, pp. 82-89, 2010.

[32] M. Garcia-Lopez, P. Canosa, and I. Rodriguez, "Trends and recent applications of matrix solid-phase dispersion," Analytical and Bioanalytical Chemistry, vol. 391, no. 3, pp. 963-974, 2008.

[33] C. M. Torres, Y. Pico, and J. Mañes, "Comparison of octadecylsilica and graphitized carbon black as materials for solid-phase extraction of fungicide and insecticide residues from fruit and vegetables," Journal of Chromatography A, vol. 778, no. 1-2, pp. 127-137, 1997.

[34] M. Navarro, Y. Pico, R. Marin, and J. Mañes, "Application of matrix solid-phase dispersion to the determination of a new generation of fungicides in fruits and vegetables," Journal of Chromatography A, vol. 968, no. 1-2, pp. 201-209, 2002.

[35] N. M. Cassiano, J. C. Barreiro, L. R. R. Martins, R. V. Oliveira, and Q. B. Cass, "Chromatographic methods validation for analysis of small molecules in biological matrices," Quimica Nova, vol. 32, no. 4, pp. 1021-1030, 2009.

[36] W. M. A. Niessen, P. Manini, and R. Andreoli, "Matrix effects in quantitative pesticide analysis using liquid chromatographymass spectrometry," Mass Spectrometry Reviews, vol. 25, no. 6, pp. 881-899, 2006.

[37] J. Zrostlikova, J. Hajslova, J. Poustka, and P. Begany, "Alternative calibration approaches to compensate the effect of co-extracted matrix components in liquid chromatography-electrospray ionisation tandem mass spectrometry analysis of pesticide residues in plant materials," Journal of Chromatography A, vol. 973, no. 1-2, pp. 13-26, 2002.

[38] A. Sannino, L. Bolzoni, and M. Bandini, "Application of liquid chromatography with electrospray tandem mass spectrometry to the determination of a new generation of pesticides in processed fruits and vegetables," Journal of Chromatography A, vol. 1036, no. 2, pp. 161-169, 2004.

[39] P. Kebarle and L. Tang, "From ions in solution to ions in the gas phase," Analytical Chemistry, vol. 65, no. 22, pp. 972A-986A, 1993. 

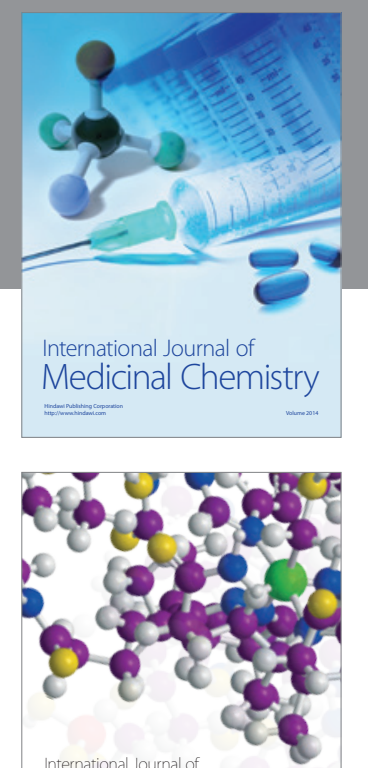

\section{Carbohydrate} Chemistry

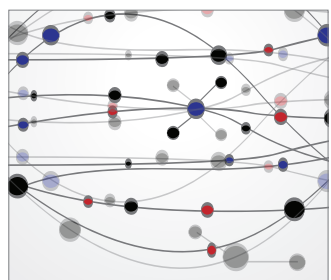

The Scientific World Journal
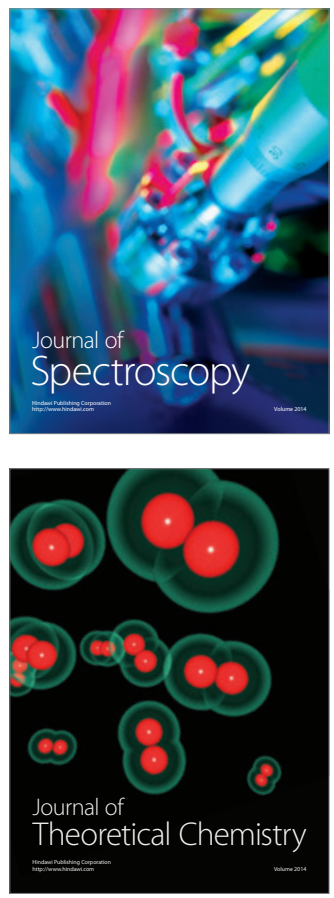
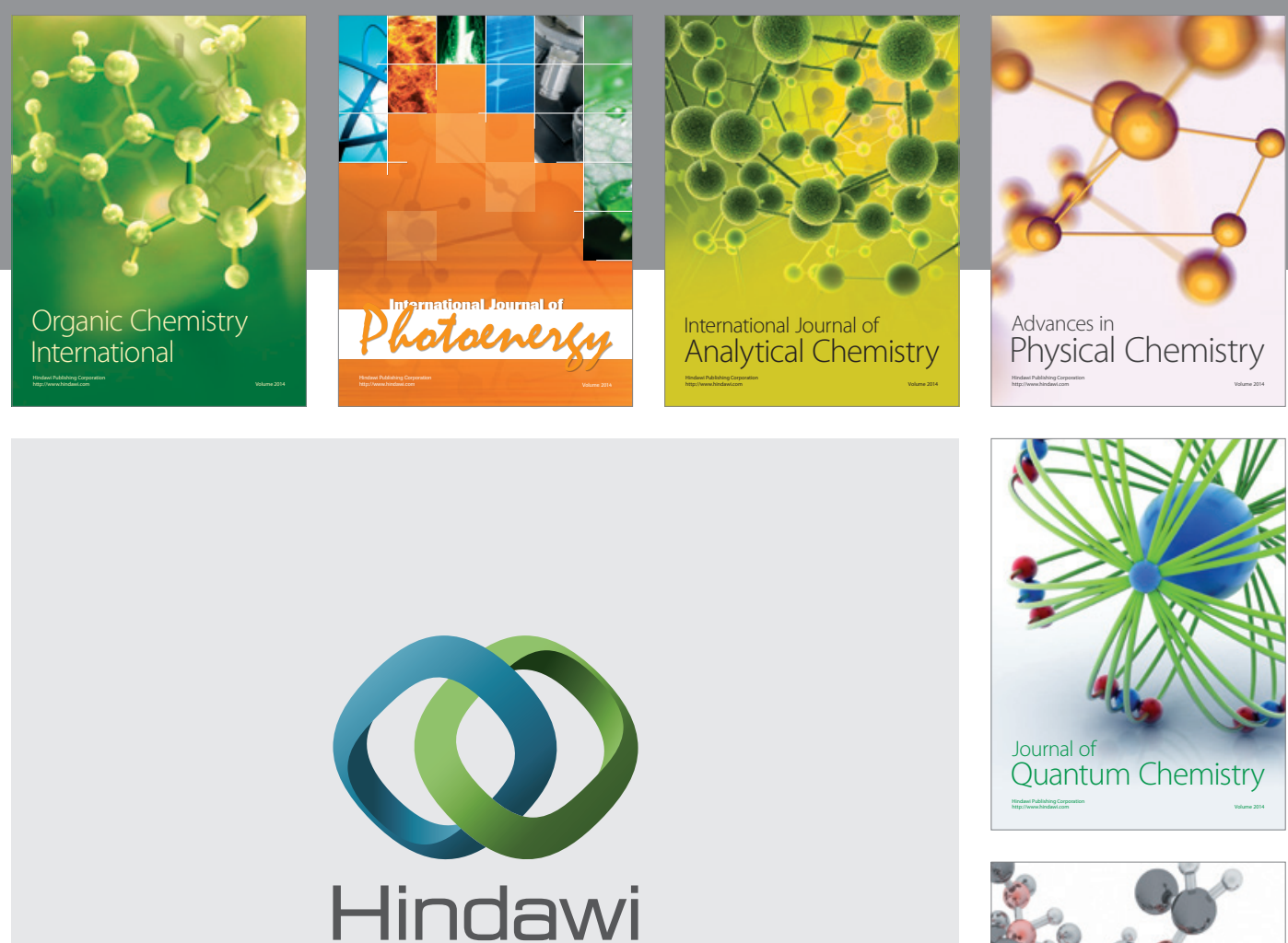

Submit your manuscripts at

http://www.hindawi.com

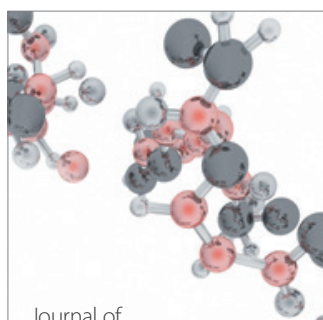

Analytical Methods

in Chemistry

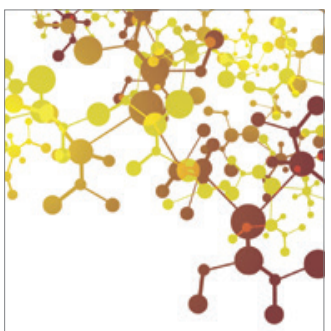

Journal of

Applied Chemistry

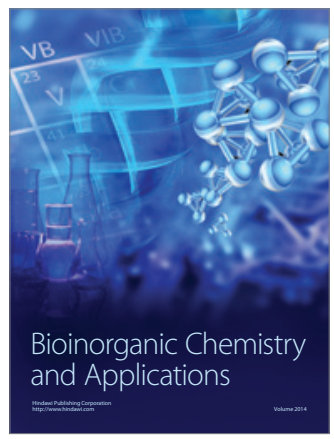

Inorganic Chemistry
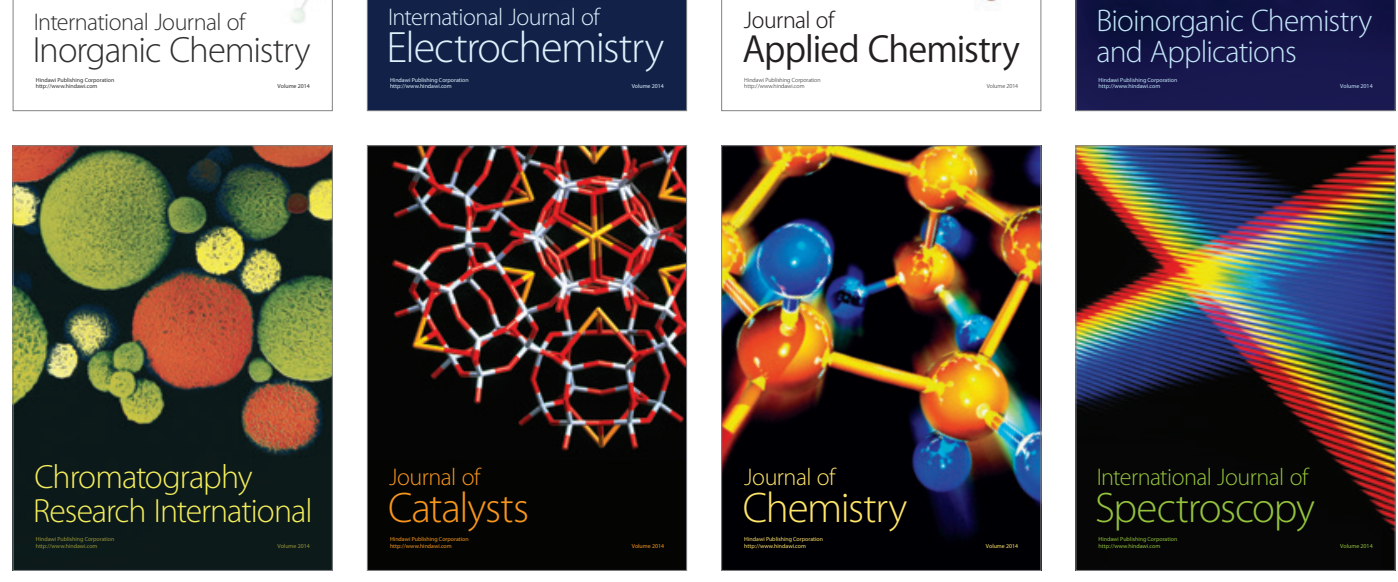